\title{
Analysis of Rolling Contact Bearings Test Data by the Bimodal Method
}

\section{Yaakov Meged}

The Faculty of Mechanical Engineering, The Technion Israel Institute of Technology, Haifa, Israel

Email: ygoodi@013.net.il

How to cite this paper: Meged, Y. (2021) Analysis of Rolling Contact Bearings Test Data by the Bimodal Method. Advances in Materials Physics and Chemistry, 11, 1-6. https://doi.org/10.4236/ampc.2021.111001

Received: December 21, 2020

Accepted: January 17, 2021

Published: January 20, 2021

Copyright () 2021 by author(s) and Scientific Research Publishing Inc. This work is licensed under the Creative Commons Attribution International License (CC BY 4.0).

http://creativecommons.org/licenses/by/4.0/

(c) (i) Open Access

\begin{abstract}
Lieblein J. and Zelen A. conducted a study of the fatigue life of deep groove ball bearings. This study was based on data of 4948 bearings as obtained from 5 companies and 213 test groups. Among these data is a detailed test report \#3183, lot 73, consisting of 23 failed bearings. This report states that the Weibull slope of this group is 2.23 , meaning that this distribution is mono sloped. These test data were plotted by the author on a bilinear scale plane, of endurance life versus bearing number and proved to be distinctly bi sloped. This basic difference prompted a wide study resulting in several new findings and set the grounds for a new analysis method.
\end{abstract}

\section{Keywords}

Bimodal Fatigue Mechanism, Deep Groove Ball Bearings, Mechanical Mode, Hydraulic Mode, Relative Intensity, Cavitation Erosion

\section{Introduction}

Rolling contact bearings operate at high stress levels, causing them to have no endurance limit, and having a finite service life. This life is rather dispersed, reaching a ratio of 20:1 between the extreme life values. The problem of finite life under fatigue loads becomes a problem of statistics, or as far as design is concerned, a question of reliability [1].

One of the methods to analyze bearing failures is the Weibull method [2]. The two-parameter Weibull distribution is by far the most widely used distribution function for life data analysis. The Weibull cumulative distribution function (CDF) has an explicit function: $F(t)=F \max [1-\exp -(t / T)]$. Slope values from 1.0 to 4.0 imply early wear-out, and characterize many mechanical failure modes, including most bearing failures. The ball bearing test report [3] presents the slope value of 2.23 , thus fitting well with the above mentioned Weibull range. 
The mono sloped Weibull plot does not diagnose the failures and their origin, requiring a further engineering study. The following study supplies several answers in order to diagnose these failures, and suggests a new method for bearing failure analysis. The new method is based on the bimodal failure concept, which considers both liquid and solid phases in the bearings as active participants in the failure process.

\section{Discussion}

\subsection{Lubricant}

The lubricant designated in the test report for bearings \#3183 lot 73 is jet oil [3]. Since this information is very limited additional data were compiled from similar present products, covered by MIL-PRF-23699-HTS. As a synthetic lubricant it has an ester base stock and several additives such as: anti-oxidants, metal passivator, defoamant, anti-wear and extreme pressure materials. Synthetic lubricants are known as highly hygroscopic liquids. The additives increase their water absorption. The water content of synthetic lubricants easily reaches levels that were found to have detrimental effect on RC bearing life [4]. Water content as low as $25 \mathrm{ppm}$ has shortened bearing service life in nearly $30 \%$. This effect is explained by the cavitation of water, which has a higher vapor pressure causing it to be more volatile [5]. Since water absorption by jet oil to dangerous levels is unavoidable, it is necessary to incorporate effective dehydration systems for the lubricant, such as Compact Membrane System (CMS) [6].

\subsection{Bearings}

The bearings studied in this paper are deep-groove ball bearings, as described in Appendix A. Designation of the test is \#3183, lot 73. The name of the company is not mentioned. Original test data are presented in Table 1, consisting of the endurance life and failed item for each bearing. The test began with 25 bearings. Two units were omitted due to bore failures, leaving a total of 23 units. The test data were potted on linear scales, see Figure 1. The plot divides the plane into three distinct zones:

1) Zone $\mathbf{A}$ : The no-failure zone reaching 17.88 million revolutions, about $10 \%$ of the total test duration.

2) Zone B: The steep part of the plot extends to 50.76 million revolutions, about $30 \%$ of the total test duration.

3) Zone C: The shallow part of the plot extends to 104.76 million revolutions, about $60 \%$ of the total test duration.

For each part of the plot the failed items are listed separately, see Table 2. The steep part of the plot contains only balls and inner rings, items that are in contact during operation. This part of the plot contains $56.5 \%$ of the tested bearings. The shallow part of the plot contains $43.5 \%$ of the bearings and two types of items which are not in contact with moving parts, namely the bore and the disc. These items fail under cavitation erosion which develops in the water-containing 
Table 1. Test data of deep groove ball bearings \# 3183, lot 73 .

\begin{tabular}{|c|c|c|c|}
\hline Bearing number & $\begin{array}{l}\text { Endurance Life } \\
\text { Million revs. }\end{array}$ & Failure type & Notes \\
\hline 16 & 17.88 & Ball & \\
\hline 10 & 28.92 & Ball & \\
\hline 5 & 33.00 & Ball & \\
\hline 19 & 41.52 & Inner ring & \\
\hline 9 & 42.12 & Ball & \\
\hline 11 & 45.60 & Ball & \\
\hline 15 & 48.48 & Ball & \\
\hline 12 & 51.84 & Ball & \\
\hline 20 & 51.96 & Ball & \\
\hline 18 & 54.12 & Inner ring & \\
\hline 13 & 55.56 & Inner ring & \\
\hline 1 & 67.80 & Ball & \\
\hline 2 & 67.80 & I. Bore & Omitted \\
\hline 3 & 67.80 & Bore & Omitted \\
\hline 4 & 68.64 & Ball & \\
\hline 6 & 68.64 & L. Bore & \\
\hline 25 & 68.88 & Disc & \\
\hline 22 & 84.12 & Ball & \\
\hline 17 & 93.12 & Ball & \\
\hline 7 & 98.64 & Inner ring & \\
\hline 23 & 105.12 & Inner ring & \\
\hline 24 & 105.84 & Disc & \\
\hline 21 & 127.92 & Ball & \\
\hline 8 & 128.04 & Outer ring & \\
\hline 14 & 173.40 & Disc & \\
\hline
\end{tabular}

Table 2. Failed items classification and location.

\begin{tabular}{cccccc}
\hline Number & Item & Zone B & Zone C & Total & Notes \\
\hline 1 & Steep slope & Shallow slope & & \\
2 & Ball & 10 & 3 & 13 & \\
3 & Inner ring & 3 & 2 & 5 & \\
4 & Disc & 0 & 3 & 3 & no contact item \\
5 & Outer ring & 0 & 1 & 1 & \\
& Bore & 0 & 1 & 1 & no contact item \\
& Total & 13 & 10 & 23 & \\
\hline
\end{tabular}




\section{FAILED BEARING}

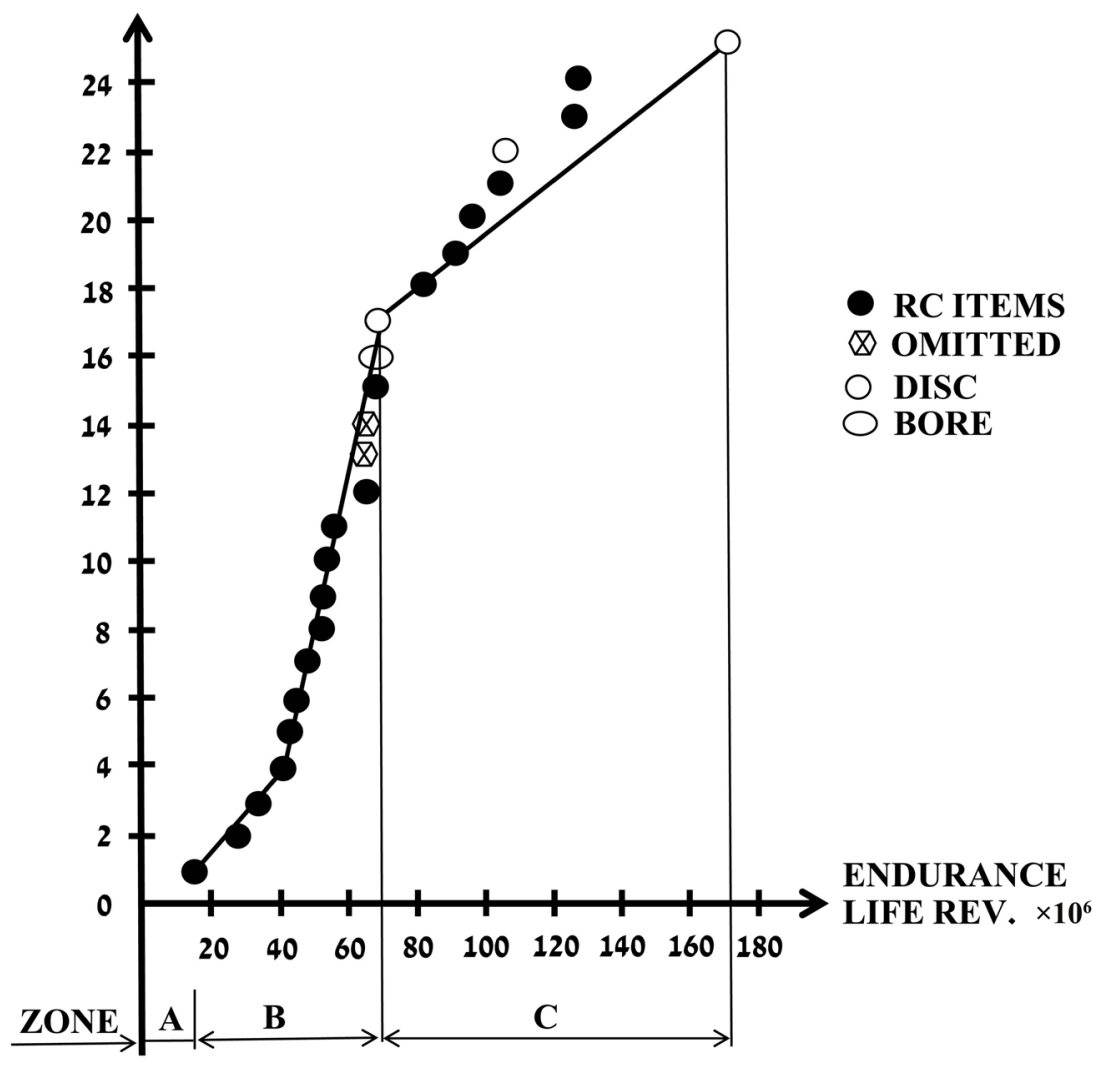

Figure 1. Test data of deep-groove ball bearıngs \#3183, lot 73 .

lubricant. As a result of this analysis the plot is considered Bimodal. Both mechanical and hydraulic failure modes prevail throughout the test simultaneously.

In estimating the relative intensity of each failure mode in this test we can apply the number of relevant failed items in each category, namely:

1) The items in-contact for the mechanical mode,

2) The non-contact items for the hydraulic mode.

From Table 2 we can obtain the following data: In zone B there are only in-contact items-13. While in zone $\mathbf{C}$ there are failed items of both categories -10 , and all of the non-contact items -4 . These estimates require further confirmation. However, they indicate that the intensity of failure mode $\mathrm{M}$ is considerably the larger.

Life span, the ratio between the extreme life values, is 3.84 for zone B, 2.53 for zone $\mathrm{C}$ and 9.7 over all the test. This relative life is nearly half of that stated by SKF as an overall range for RC bearings.

\section{Conclusions}

\subsection{Test Omission}

Bearings \#2 and \#3 (see Table 1), were omitted from the test after 67.8 million revolutions due to bore failures. The bore is in no contact with the rotating bearing parts. Therefore, the only way by which it can be damaged is by cavita- 
tion erosion of the lubricant. These failures occurred after a rather long exposure of 565 hours to cavitation erosion and can therefore be considered as legitimate failures of mode $\mathrm{H}$. These omitted bearings are inconsistent with the approval of bearing \#6, which had bore failure, too.

\subsection{Similarities of Test Results}

RC bearing life is assessed by several methods, three of which are further compared: Statistics, Weibull and the bimodal method. They all bear a high degree of similarity concerning the following aspects of this analysis:

1) The median is 68 million revolutions, the mean is 71 million revolutions and the transition point between both slope lines is at 68.8 million revolutions.

2) The Weibull slope is 2.28 and the slope of zone $\mathbf{B}$ with most mechanical failures is 2.3 .

\subsection{Dissimilarities of Test Results}

Test report 3183 states that the Weibull slope of the test results is 2.23 . This infers that the distribution of this group of bearings is unilineal. However, the plot in Figure 1 clearly indicates that it is bilinear and bimodal. This is a significant difference which is the basic cause of this analysis. It further enables comparing both zones, via slopes contents and densities. Comparison of these parameters indicates that the intensity of mode $\mathbf{M}$ in this test is larger than that of mode $\mathrm{H}$.

\subsection{Test Data}

This analysis is based on limited data that enable internal comparisons between types of failed items and between failure modes. It clearly indicates the existence of water in the lubricant and its detrimental effect in causing cavitation erosion on bearing parts. Test data are proprietary and scarce. Much more is required for additional quantitative evaluations.

\subsection{Water Contaminated Lubricant}

Jet oil was used to lubricate the bearings in test \#3183 [3]. The lubricant is synthetic and contains several additives. As such it is hygroscopic and may cause cavitation erosion and damage in the bearings.

The quantity of water in the lubricant is further estimated by applying a di-ester lubricant \#9, studied by Cantley [4]. Exposure of this liquid to air with a relative humidity of $20 \%$ caused the water content to reach $750 \mathrm{ppm}$. This value is much higher than that tested in full-scale RC bearings, $25 \mathrm{ppm}$, and found to shorten their service life appreciably. This study clearly indicates that the lubricant in test \#3183 contained a large amount of water, thereby causing cavitation erosion in the tested bearings.

\section{Conflicts of Interest}

The author declares no conflicts of interest regarding the publication of this paper. 


\section{References}

[1] Phelan, R.M. (1962) Fundamentals of Mechanical Design. McGraw Hill, New York, 436.

[2] Abernathy, R.B. (1976) The New Weibull Handbook. 2nd Edition.

[3] Lieblein, J. and Zelen, M. (1956) Statistical Investigation of Fatigue Life of Deep Groove Ball Bearings. Journal of Research of the N.B.S, 57, 2717. https://doi.org/10.6028/jres.057.033

[4] Cantley, R.E. (1976) The Effect of Water in Lubricating Oils on Bearing Fatigue Life. ASLE Transactions, 20, 244-248. https://doi.org/10.1080/05698197708982838

[5] Meged, Y. (2020) Bimodal Failure Mechanism of Rolling Contact Bearings. Advances in Materials, Physics and Chemistry, 10, 230-238. https://doi.org/10.4236/ampc.2020.1010017

[6] Williamson, A. (2020) Machinery Lubrication Engineering.

\section{Nomenclature}

$\mathrm{C}=$ cavitation

$\mathrm{CDF}=$ cumulative distribution function

$\mathrm{CE}=$ cavitation erosion

CMS = compact membrane system

$\mathrm{e}=$ base of natural logarithms

$\mathrm{F}=$ fraction failure $\%$

$\mathrm{RCB}=$ rolling contact bearings

$T=$ time constant

\section{Appendix A: Deep Groove Ball Bearings Tested [3]}

1) Bearing type: Deep groove

2) Ball diameter: $1 / 4^{\prime \prime}$

3) Number of balls: 9

4) Bore diameter: $20 \mathrm{~mm}$

5) Outer diameter: $42 \mathrm{~mm}$

6) Test date: August 26, 1946

7) Test number: 3183

8) Lot number: 73

9) Load: 500 R.L

10) Rotation Speed: $2000 \mathrm{rpm}$

11) Report date: March 22, 1956 